\title{
Low Speed Rear End Automobile Collisions and Whiplash Injury, the Biomechanical Approach
}

\begin{abstract}
ALlan F. TENCER
Abstract The extent of injury in low speed rear end collisions is controversial. In many cases, the impact speed of the striking vehicle is low, neither car shows much if any post collision damage, and at the scene, the occupant of the struck vehicle appears uninjured. Yet many of these incidents progress to lawsuits with sometimes very significant damage and injury claims. In testimony, Plaintiff argues that the collision was significant while Defendant describes the collision as minor. A Biomechanical approach which addresses the forces in the collision and the resulting forces and kinematics of the occupant can help to resolve some of these issues. In the following, the process of a biomechanical analysis is described, using a specific example. A discussion of how courts have viewed this type of testimony is then presented.
\end{abstract}

Keywords: - Biomechanics - Rear End Collisions - Cervical Spine • Whiplash • Injury •

CORRESPONDENCE ADDRESS: Allan Tencer, University of Washington, Department of Orthopedics and Sports Medicine, Seattle, Washington, United States of America, e-mail: allantencer@gmail.com. 


\section{Introduction}

Whiplash injuries to the cervical spine resulting from rear-end motor vehicle accidents continue to be the single most expensive medical claim to insurers (Insurance Institute for Highway Safety, 1995; Holm et al., 2008). Diagnosis of cervical spine whiplash is often confounded by a general lack of objective symptoms but may result in a long lasting chronic condition (Barnsely et al., 1995; Deans et al., 1987; Radanov \& Sturzenegger, 1996; Spitzer et al, 1995, Yadla et al., 2008). In the United States, head restraints were introduced into vehicles in 1969 with the aim of limiting excessive backward bending of the head and neck over the back of the seat. Though this reduced the incidence of reported neck injury from $29 \%$ to $24 \%$ (O’Neill et al, 1972), in more recent studies, a significant number of occupants still report neck symptoms (Eis et al, 2005, Krafft et al 2005, Bartsch, et al, 2008, Merrick \& Stalnacke, 2010). Partly, this was attributed to poor adjustment of the head restraint which was still too low or too far behind the occupant's head to be effective (Tencer et al., 2000). Both the Insurance Corporation of British Columbia (www.icbc.com) ${ }^{1}$ and the Insurance Institute of for Highway Safety (www.iihs.org) ${ }^{2}$ have safety programs related to head restraint performance and adjustments. In 2008 the US National Highway Traffic Safety Administration introduced a new safety rule regarding the design of head restraints (US Dept of Transportation, 2008). Regardless of these efforts, injury claims and lawsuits from rear end collisions still occur with significant frequency, (Sarrami et al., 2017).

The following describes a biomechanical approach to help to resolve these claims, based on extensive research into the transmitted collision forces in rear-end collisions and the responses of occupants in terms of kinematics and tolerable forces. While the process of a law suit is adversarial and the biomechanical engineer testifies for one side, a biomechanical analysis itself is an objective assessment of the collision. First, the basic process of the analysis is described. Then, a discussion is provided of various United States court opinions on the limitations and acceptance of this testimony based on this author's experience.

\footnotetext{
${ }^{1}$ https://www.icbc.com/road-safety/safer-drivers/Pages/Adjusting-head-restraints.aspx

${ }^{2}$ https://www.iihs.org/news/detail/neck-injury-risk-is-lower-if-seats-and-head-restraints-are-ratedgood
} 


\section{Biomechanical Assessment Process}

\section{$2.1 \quad$ Overview}

The process of a biomechanical assessment involves three parts. First the speed of impact of the striking vehicle is assessed and the speed change and acceleration of the struck vehicle are calculated. Second, the forces transmitted to the occupant are determined. Third, the occupant forces are described in terms of forces that are known in the biomechanics community to be "tolerable". The jury can use this information to assess the credibility of the Plaintiff's and Defendant's descriptions of the accident. Although not the specific intention of the biomechanical testimony, the jury may infer whether the forces were or were not sufficient to cause injury and if so, its severity. The following provides more details of the steps of the biomechanical analysis.

\subsection{Impact Speed Calculation Basics}

Figure 1 below shows some still photographs from a video of a staged rear end collision. The vehicle on the left (the struck vehicle) is stopped. In the top image, the striking vehicle (on the right) is approaching at about $7.5 \mathrm{mph}(12 \mathrm{kph})$. In the middle image, the vehicles are in contact, bumper to bumper. In the bottom image the striking vehicle hass stopped while the struck vehicle moves forward at about $6 \mathrm{mph}(9.6 \mathrm{kph})$.

This process is an example of a transfer of momentum from the striking to the struck vehicle. Momentum is defined as the product of the mass of an object and its velocity. A classic example of momentum transfer is the familiar game of billiards. When the white (cue) ball is struck, it rolls forward, strikes a target ball and stops. It transfers its momentum to the target ball which rolls forward (hopefully into the pocket). The process is similar for vehicle to vehicle contacts. In the billiard ball example, the impact is called almost "perfectly elastic" because the balls are made of hard plastic and do not deform (only microscopically). The momentum of the cue ball is almost completely transferred into forward velocity of the target ball. If the balls were made of bread dough they would squash upon contact and the target ball would barely move forward (an inelastic collision). In this case the momentum of the cue ball is transferred mainly into deforming the two balls as they contact and results in almost no forward velocity of the struck ball. This collision property (restitution) has a significant effect on the forward velocity of the struck vehicle in a collision. 
The elasticity of the collision is defined by a number between 0 and 1 which is termed the coefficient of restitution (COF). Steel on steel bumper collisions, typically between trucks at low speed, act mostly like plastic billiard balls, so truck collisions can be calculated using a coefficient of restitution (COF) of nearly 1.0 (unless there is significant bending of the bumper or the frame). Most bumpers on modern cars utilize foam energy absorbers behind the front bumper cover and are partly elastic and partly compressible. Experimental data for foam bumpers gives COF values from about 0.3 to 0.1 , decreasing as impact speed increases (Howard, Bomar \& Bare, 1993; Tanner et al., 2001).

The process of calculation of the speed change and acceleration of the struck vehicle requires knowledge of the impact speed of the striking vehicle, the weights of the vehicles, and the COF value based on the types of bumpers and the level of damage. The calculation method (Momentum, Energy, Restitution or MER) is based on the physical principal of Conservation of Momentum, that is, when one object strikes another, the total momentum before and after the collision remains the same. Details of the calculation method are widely available and specific steps of the application to low speed collisions are given in a number of references (Siegmund, King \& Montgomery, 1996; Happer, Hughes, Peck \& Boehme, 2003).

The computation provides the speed change of the struck vehicle and its forward acceleration. Speed change is simply the speed of the struck vehicle after the collision subtracted by the speed before the collision (which in many rear end collisions is zero since the struck vehicle was stopped before impact). The acceleration is the speed change divided by the time of the event (the time of contact between the bumpers). Acceleration is important since it defines the force that will act on the occupant. The following provides a specific example of the process. 
MEDICINE, LAW \& SOCIETY

A. F. Tencer: Low Speed Rear End Automobile Collisions and Whiplash Injury, the

Biomechanical Approach
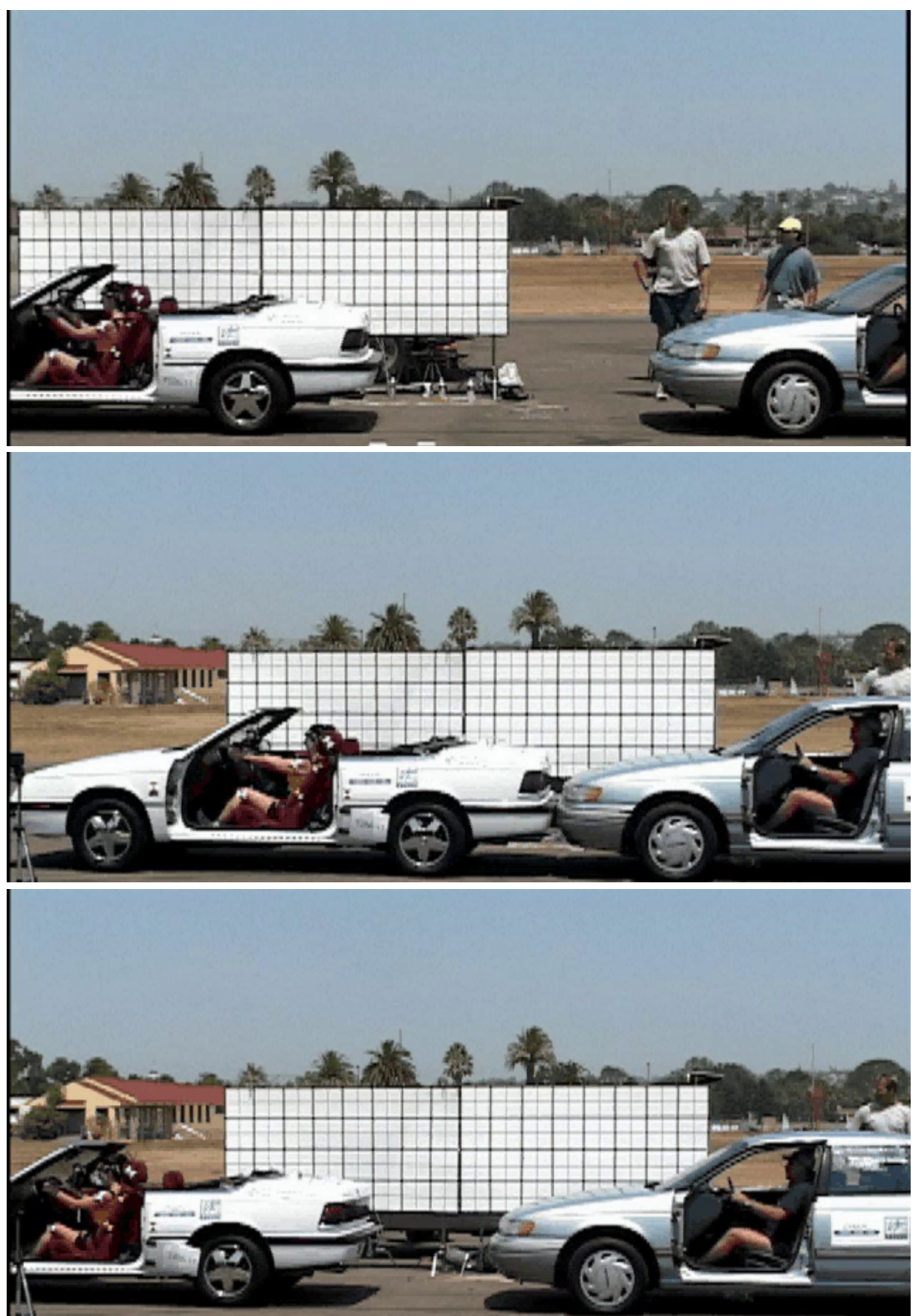

Figure 1 (top): The striking vehicle on the right approaches the stopped struck vehicle, (middle) the vehicles are in contact, (bottom) the striking vehicle rolls slightly forward and stops, while the struck vehicle is accelerated forward. (from the video »machine $\mathrm{v}$ man«) 


\subsection{Determining the Striking Vehicle's Impact Speed and Struck Vehicle Speed Change and Acceleration}

The first step in the process is a damage assessment of the striking vehicle so that the speed of the striking vehicle upon impact can be determined. The impact speed affects the speed change of the struck vehicle and its resulting forward acceleration so is an important variable in the analysis. Vehicle damage after a low to moderate speed collision can be deceptive. Shown in Figure 2 (top) is the front end of a Ford Mustang which on the outside bumper cover shows very little damage. A small crack at the center of the bumper cover and slight misalignment of the bumper cover from a side view appear to be the limits of damage. However, as shown in Figure 2 (bottom), there was significant hidden damage to the Mustang's bumper which was only evident after a teardown. This occurred because the bumper cover is flexible and can return to its original shape after impact concealing damage behind it. Figure 3 shows the rear of the struck vehicle, a Lexus, which appears to have only scuff marks on its rear bumper. 
MEDICINE, LAW \& SOCIETY

A. F. Tencer: Low Speed Rear End Automobile Collisions and Whiplash Injury, the

Biomechanical Approach
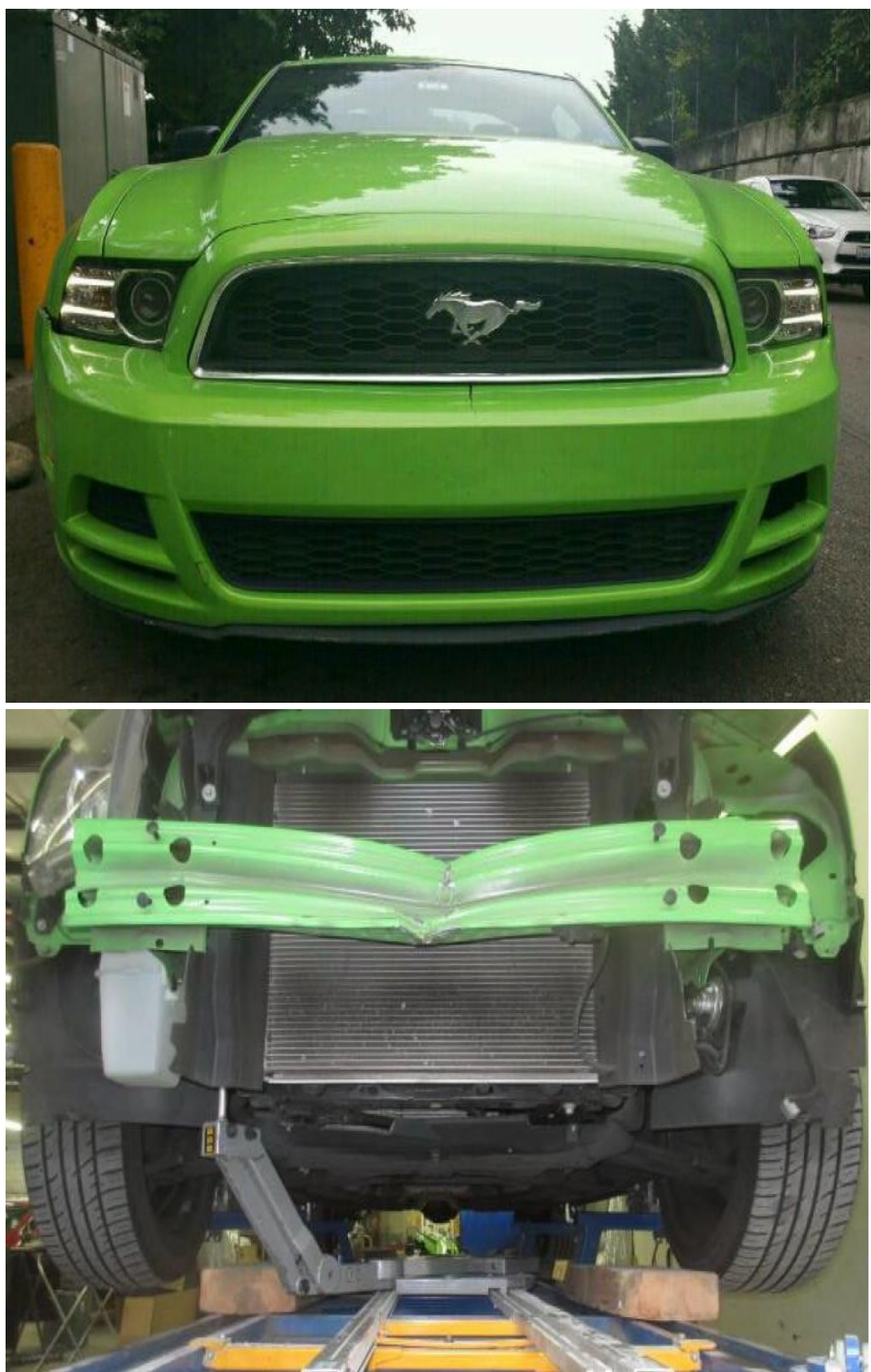

Figure 2 (top) The front bumper of a Ford Mustang in a rear end collision, (bottom) After teardown, significant damage to the front bumper beam was revealed. 


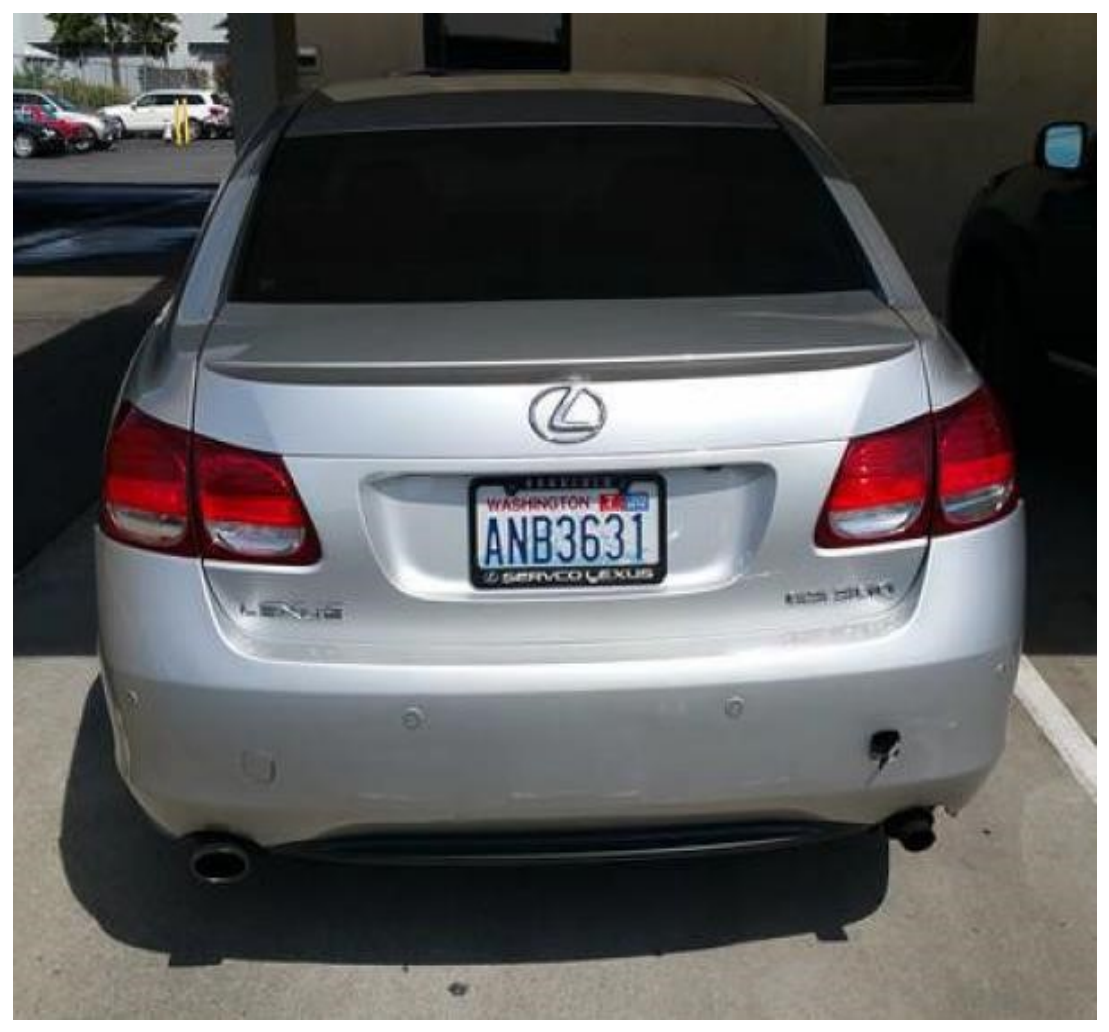

Figure 3 View of the Lexus which was stuck buy the Mustang

Several methods can be used to determine the approximate impact speed of the striking vehicle, depending on the level of damage. As shown in Figure 4, modern bumpers are quite simple, having a flexible plastic cover with no structural value, a foam energy absorber, and a steel beam mounted to the unibody frame of the vehicle. 


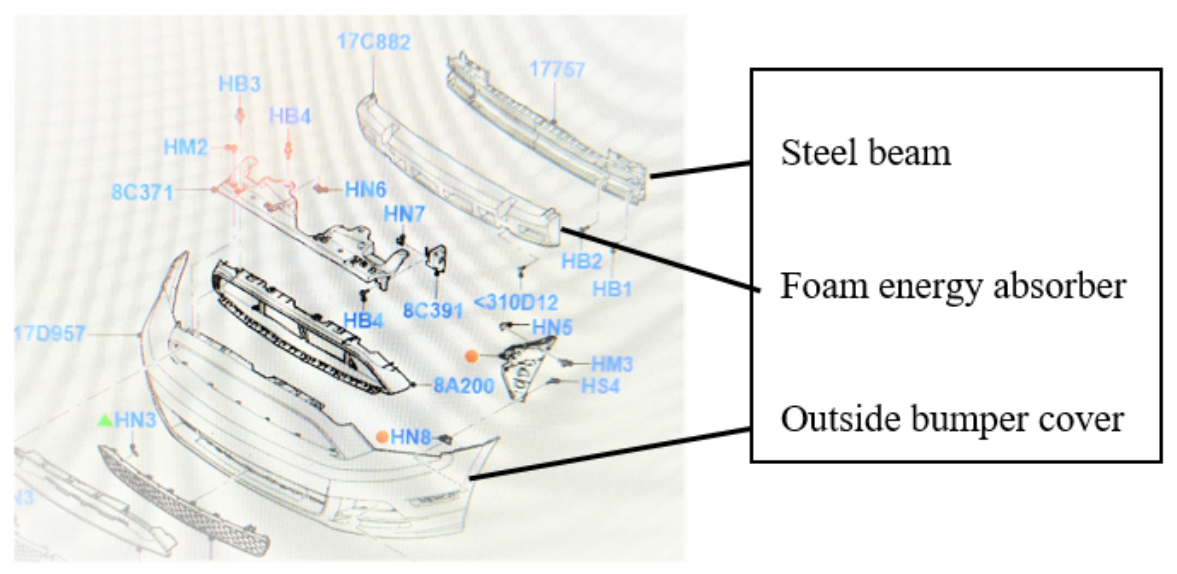

Figure 4 Parts diagram of the Ford Mustang bumper

In one method, where damage occurs only to the bumper cover or cover and foam absorber, a reasonable approach is to compare the damage from a damage estimate and photos of the striking vehicle to the results of a bumper test of a similar vehicle performed by the Insurance Institute for Highway Safety (IIHS www.iihs.org). The IIHS tests bumpers by pulling the vehicle into a rigid barrier at $6 \mathrm{mph}$ and assessing the resulting dollar amount of damage. To obtain a more precise estimate of impact speed, in our laboratory, we tested the impact properties of a variety of foam absorbers to determine the equivalent vehicle speed to cause damage, (equating energy absorbed by the foam to kinetic energy of the vehicle). This method of analysis provides a reasonable upper range estimate of the striking vehicle impact speed.

Once the striking vehicle speed is estimated, a Conservation of Momentum (MER) analysis can be performed. The basics of the method were described above. Knowing the impact speed, the running weights of the Mustang ( $3708 \mathrm{lbs} / 1685 \mathrm{~kg}$ ) and the Lexus (3816 $1 \mathrm{bs} / 1734 \mathrm{~kg}$ ) and using a COF of 0.1 because the steel beam was bent, the speed change and acceleration of the Lexus was determined. Common engineering analyses of crashes use a "crush method" which depends upon how much residual crush is present in the vehicles. In low speed collisions there is usually negligible residual crush so the crush method is not applicable to these cases (Happer et al., 2003). 
In this particular case of the Ford Mustang, a third method was employed to estimate the Mustang's impact speed, since damage occurred behind the foam absorber, specifically to the steel beam. From Newton's $3^{\text {rd }}$ Law, the forces acting on the Mustang and the Lexus at impact were equal in magnitude but opposite in direction. Therefore, the force to bend the Mustang's bumper was equal to the force that accelerated the Lexus. The force to bend the Mustang's bumper came from a beam analysis, similar to the analysis that structural engineers employ to calculate the load and deformation in beams used in bridges and buildings. Given the material properties, shape, length, and deformation of the bumper beam, the force required to deform it was determined. As mentioned, this force is the same in magnitude as that acting on the Lexus. Newton's $2^{\text {nd }}$ Law gives a relation between the force acting on the Lexus, the mass of the Lexus and its resulting acceleration. In this case, the acceleration of the Lexus was calculated as $4 \mathrm{G}$, its speed change as $6.5 \mathrm{mph}(10.5 \mathrm{kph})$, and the impact speed of the Mustang was about $13 \mathrm{mph}$ (20.9 kph). Engineers usually express the acceleration in " $G$ " units where $G$ is the freefalling acceleration of an object under gravity. (the acceleration, 4G can be compared to that of a Formula 1 racecar which can accelerate at about $1 \mathrm{G}$ or $22 \mathrm{mph} / \mathrm{sec}(35.4$ $\mathrm{kph} / \mathrm{sec}$ ). Note that the Lexus only reached a speed of about $6 \mathrm{mph}$ because the acceleration only occurred for a fraction of a second (the time the car bumpers were in contact).

\subsection{An Alternative Method for Determining Speed Change and Acceleration}

A more accurate method of determining the speed change and acceleration of the struck vehicle comes from downloading data from its event data recorder (EDR) or "black box". Most vehicles after about model year 2012 have this module which records data during an impact event. Data from an example EDR recording is shown in Figure 5.

This record, from an actual rear end crash (not the Mustang-Lexus impact) shows a plot of speed in miles per hour (MPH) as a function of time post impact in thousandths of a second (milliseconds) that was recorded by an EDR. The maximum speed of the vehicle, which in this case was initially stopped (at $0.0 \mathrm{msec}$ ), reached $6.2 \mathrm{mph}$ at $70 \mathrm{msec}$. Though the actual final speed was not high, it took a very short time to reach this speed indicating the acceleration was high. Had this acceleration lasted just 1 second $(1000 \mathrm{msec})$ the vehicle speed would have been $88.5 \mathrm{mph}$. (By comparison a formula 1 race car can accelerate to the same speed in about 4 seconds). 


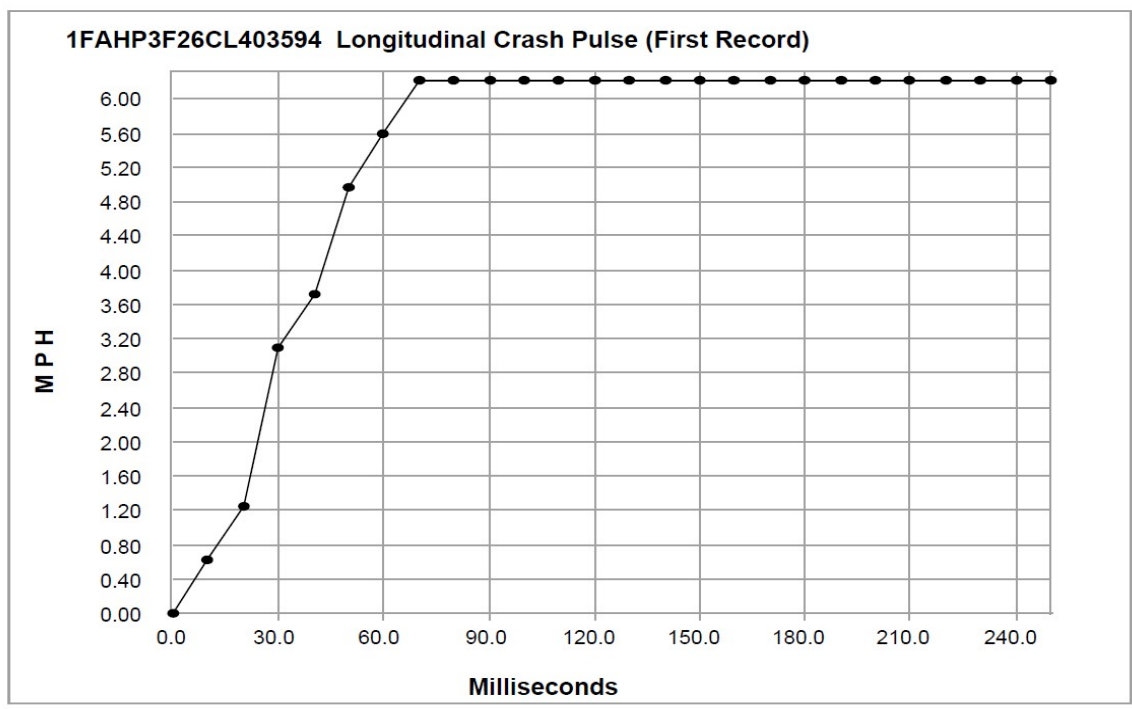

Figure 5 Example recording from an event data recorder from a struck vehicle in a low speed collision

\subsection{The Motion of the Occupant's Body During a Rear End Collision}

Once this part of the analysis has been completed, we move forward to the occupant. The motion of the occupant in a rear end collision is shown in the sequence of photos below in Figure 6. In the top image, the occupant is seated facing forward just prior to the collision (note the sequence parallels that of the car to car impact shown in Figure 1 above. As the struck vehicle is impacted, it is pushed forward toward the occupant. The occupant goes backward, relative to the seat but really it is the seat going forward into the occupant. Figure 6 (middle) shows the occupant compressing the seat and head restraint. It can be appreciated that an effective head restraint which is high enough will keep the occupant's head and torso reasonably well aligned. The crux of the whiplash injury mechanism is that when the head and torso are not well aligned, the neck, which is the connection between the head and the torso, is stressed. In Figure 6 (bottom) the occupant has rebounded forward from the compressed seat and head-restraint. 
A. F. Tencer: Low Speed Rear End Automobile Collisions and Whiplash Injury, the Biomechanical Approach

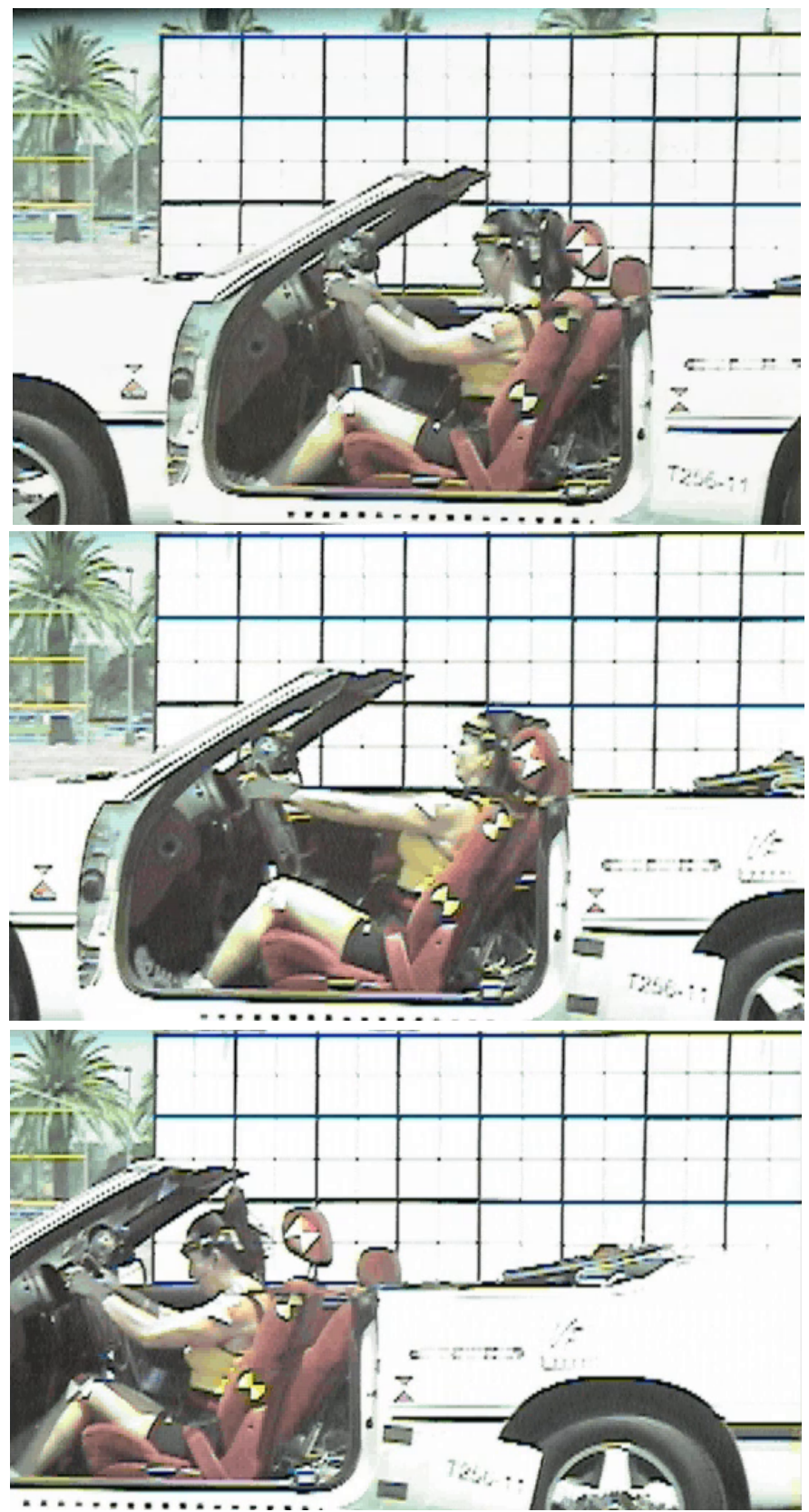

Figure 6: Movement of the occupant, from top, pre impact, impact, post impact. 
As is apparent from Figure 6, there are several forces acting on the neck during this event (Tencer, Mirza \& Bensel, 2002). One major force, Figure 7, (second figure from left) involves shearing of the intervertebral joint. As the torso contacts the seat and is starting to be pushed forward, the head is still moving backward setting up a horizontal shear force between the vertebrae. A second mechanism involves hyperflexion (excessive forward bending). When the occupant rebounds forward, the motion of the torso is stopped by the shoulder and lap belts. However, the motion of the occupant's head is unrestrained and relies on the muscles, ligaments, and intervertebral discs in the neck which can be a source of strained tissues (Tencer, Mirza \& Bensel, 2001; Tencer, Mirza \& Huber, 2003; McConnell et al., 1995; Ono et al., 1997).

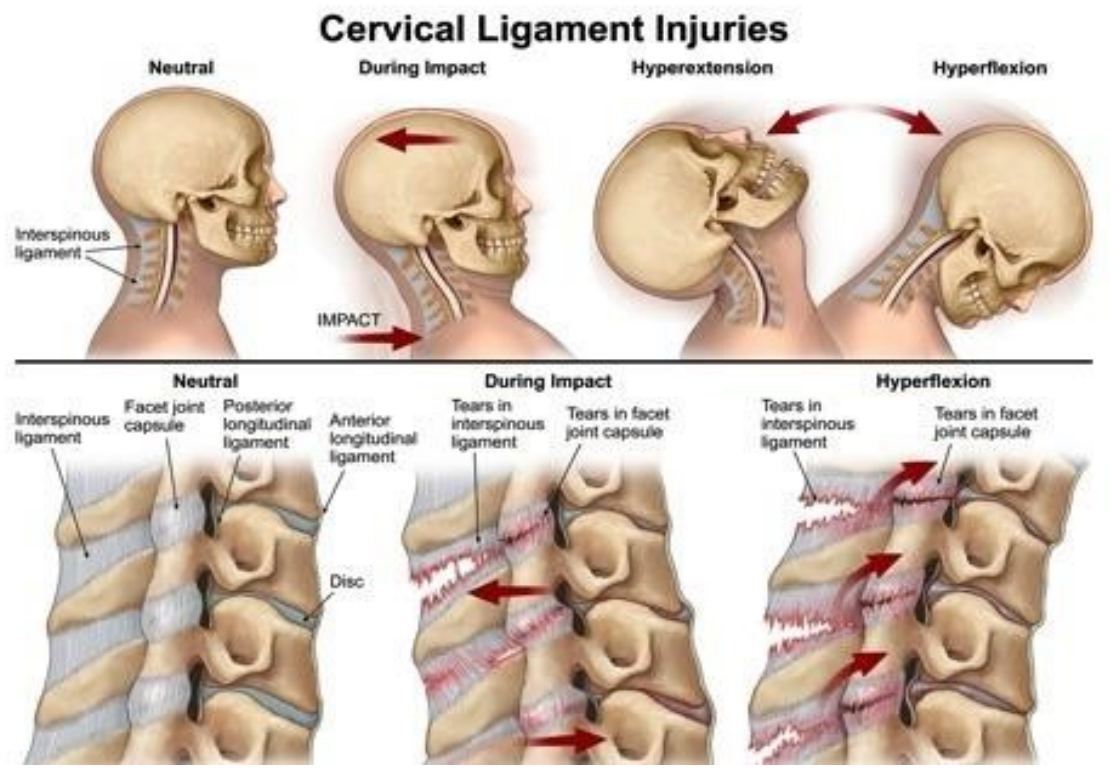

Figure 7: Mechanisms of whiplash injury, from top left, the occupant's head is upright over the torso pre impact. As the occupant contacts the seat (usually before the head impacts the head restraint) the torso starts to move forward while the head is still moving backward setting up a horizontal shearing force in the cervical spine. As the occupant moves forward after rebounding from the seat, the torso's motion is stopped by the shoulder belt while the motion of the head is unrestrained and relies on the tissues (muscles, ligaments, and discs) of the neck to stop its forward motion. 


\subsection{Forces Acting on the Head and Neck}

Clearly, there is a relationship between the severity of the impact, measured by the forward acceleration of the struck vehicle, including the seat, and the force delivered to the occupant. From a biomechanics point of view, the head acts like a large weight on top of the flexible cervical spine, bending the spine forward (flexion) during the impact event. Using experimental data from a variety of volunteer test results, the relationship between the impact acceleration of the struck vehicle and the occupant's head has been established (Tencer \& Mirza, 2000). One set of data is shown in Figure 8 relating the peak acceleration of the struck vehicle and the linear forward acceleration of the occupant's head. A significant variable affecting this relationship is how far forward the occupant was seated with respect to the head restraint which explains some of the scatter in the data. Even though the specific head to head restraint distance in a particular impact case is usually unknown, a reasonable upper limit for head acceleration can be established, by considering a worst case scenario using the upper bounds (statistically the 95\% confidence limit) of the data of Figure 8. In some cases photos of the occupant in the vehicle are available post collision to provide a better estimate. For this particular case of the Mustang v Lexus collision, the head forward acceleration was determined to be $7.8 \mathrm{~g}$. From numerous experiments with volunteers the head acceleration is usually about twice that of the vehicle acceleration (in this case $4 \mathrm{~g}$ vehicle and $7.8 \mathrm{~g}$ head).

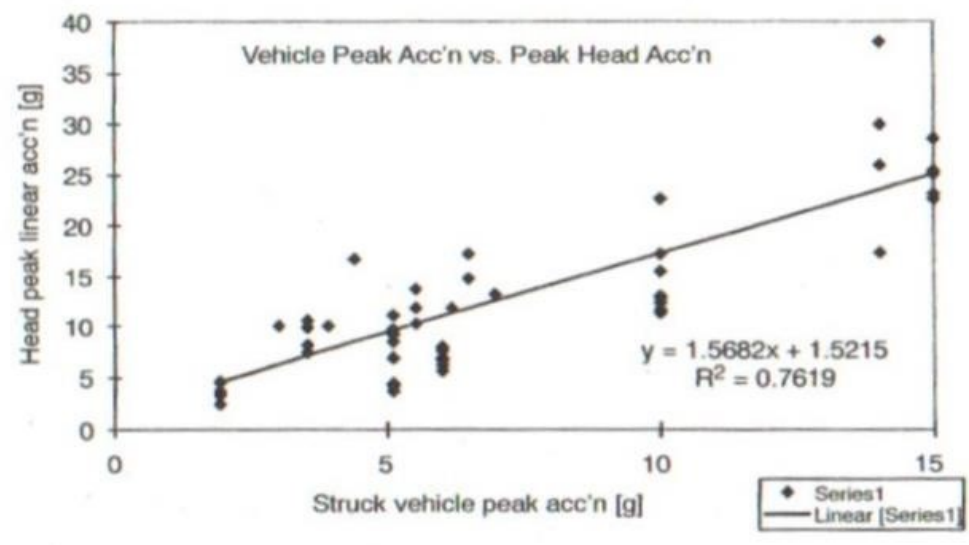

Figure 8: Relationship between the peak acceleration of the struck vehicle and the linear forward acceleration of the head in a rear end collision based on experimental data with human volunteers (Tencer \& Mirza, 2000). 
The actual flexion force on the neck is described as a bending moment. A moment is a force that acts like a lever to produce bending of the spine. In this whiplash event, the head is some distance above the base of the cervical spine (the distance from the center of gravity of the head, at about ear level, to the junction of the cervical and thoracic spines, C7-T1). As shown in Figure 7, as the occupant's head moves forward, it bends the cervical spine. The force acting at the head's center of gravity can be estimated from Newton's $2^{\text {nd }}$ Law, where the mass is the weight of a typical adult male or female head (about $10.5 \mathrm{lbs}, 4.8 \mathrm{~kg}$ ) and the acceleration is derived from the data of Figure 8. Then, the bending moment can be computed from the force acting at the head times the head to base of spine distance. In the example, the value calculated was about $28 \mathrm{ft}-\mathrm{lbs}(38 \mathrm{~N}-\mathrm{m})$. (There is an additional small value because the head also rotates downward during the motion. A relationship similar to that of Figure 8 was developed in order to estimate the additional bending load due to head rotation (Tencer \& Mirza, 2001).

As can be appreciated, the head acceleration, head weight and head CG to base of spine distance are usually estimated from available data for adult males or females. It should be noted that the approach is to make a worst case estimate so that the influence of these variables are minimized.

\subsection{Conclusions From the Analysis}

At this point the biomechanical analysis has established that the Mustang impacted the rear of the Lexus at about $13 \mathrm{mph}$ (about $21 \mathrm{kph}$ ) pushing it forward to a maximum speed of about $6 \mathrm{mph}(9.6 \mathrm{kph})$ with an acceleration of about $4 \mathrm{~g}$. The resulting acceleration of the Lexus caused the occupant to impact the seat and head restraint. The head was accelerated over the occupant's torso at about $7.8 \mathrm{~g}$ and produced a forward bending force on the cervical spine of about $28 \mathrm{ft}-\mathrm{lbs}$. All of this information was based on the objective analysis described above.

Considering other evidence in this particular example, the police report stated that "none of the parties involved reported injuries at the scene". The Plaintiff's chiropractor reported that the Plaintiff suffered "Post Concussive syndrome, Cervical, Thoracic, and Lumbar sprain/strain, Cervicalgia, paraspinal myospasms, headache, dizziness, left leg and left shoulder pain"and required long term treatment. The independent medical assessment requested by the Defense indicated that the Plaintiff suffered minor sprains requiring moderate treatment. This claim for treatment and other costs was the basis for the lawsuit. 
The biomechanical analysis can provide assistance to the jury, presented with this conflicting testimony, by putting the calculated cervical spinal load from the collision into perspective. There is a standard entitled SAE J885-12 (Society of Automotive Engineers, 2012) which is used in the assessment of the crash performance of automobiles offered for sale in the USA. All vehicles, by federal law must undergo a specified frontal and side impacts with various occupant loads measured using anthropomorphic test subjects (ie crash test dummies). Among many other measures, the standard describes the dynamic "tolerable" load in forward bending as $65 \mathrm{ft}-\mathrm{lbs}(88.2 \mathrm{~N}-\mathrm{m})$ based on the 50th percentile adult male. Also it defines the maximum static flexion load that volunteers were able to resist to be about $40.5 \mathrm{ft}-\mathrm{lbs}(54.9 \mathrm{~N}-\mathrm{m})$. Clearly though, there are differences in the maximum tolerable and resisting loads within the population. Other data (Foust, Chaffin, Snyder \& Baum, 1973) shows that, based on the maximum static flexion load being produced by 50th percentile males defined in the standard, an elderly male would achieve about $86 \%$ of the maximum voluntary value, a young female, about $66 \%$, and an elderly female, about $46 \%$. This particular Plaintiff was a 48 year old male. Therefore, the biomechanical conclusion was that the cervical spine bending force during the collision was about $70 \%$ of the maximum that he should be able to resist by voluntary contraction of his cervical muscles and $43 \%$ or the maximum tolerable load without injury.

\section{3}

\section{Acceptance of the Testimony in Trial}

Clearly, biomechanical testimony can be quite powerful since it relies on objective assessments of physical damage and the results of extensive experimentation. It is unlike the conflicting testimony usually provided by Plaintiff and Defendant and the doctors who testify for each party, because there is only one result, regardless of whether the Biomechanical engineer is testifying for Plaintiff or Defendant. Naturally, therefore it has been subjected to many challenges throughout the years.

I am not a legal scholar or a lawyer so I can only provide my experience in terms of how courts have dealt with my testimony specifically. In 2002 my testimony was challenged in a case entitled Ma'ele $v$ Arrington (Washington State Appelate Court Division 2, Ma'ele v. Arrington, 565, 111 Wn. App. 557). The Appellate court concluded that:

"Tencer opined that the maximum possible force in this accident was not enough to injure a person. And this was not a medical opinion; Tencer expressed no opinion about Ma'ele's symptoms or possible diagnosis from those symptoms. He did not say that Ma'ele was uninjured in the crash, although the jury was entitled to infer that from his testimony. Tencer 
simply testified about the nature of the forces involved in low speed collisions and the likelihood of injury from such forces."

In 2010 another case, regarding very similar testimony, Steadman v Cooper reached the Appellate Court (Washington State Appellate Court Division 1, Stedman v Cooper, 172 Wn App 9, 292). In this case, the Court gave an opposite opinion, allowing the exclusion of my testimony:

"Emphasizing that he testifies from a biomechanical rather than a medical perspective, he disavowed any intention of giving an opinion about whether Stedman could have been injured in the accident because the force was too small. Indeed, according to Cooper's brief, Tencer's conclusion was exactly that: the forces generated by the impact were not sufficient to cause the type of injuries Stedman was claiming."

In 2013, there was yet anther challenge to my very similar testimony in the case of Johnson-Forbes v Matsunaga (Washington State Appellate Court Division 2, JohnsonForbes v Matsunaga, 177 Wn. App. 402, 311 P.3d 1260 (2013)). In that matter the court agreed that my testimony should be allowed and this case actually reached the Washington State Supreme Court which concurred with the Appellate Court ruling:

„Johnson-Forbes challenges Tencer's expert testimony as improper medical opinion ... the clear message was that this collision could not have injured the Plaintiff. We disagree that Tencer's testimony was medical in nature. Significantly, Tencer did not offer an opinion about whether the forces involved in the accident would or would not have caused personal injuries to anyone in general or to Johnson-Forbes in particular ... Tencer limited his testimony to the forces generated in the collision and his conclusion was not likely the source of significant forces... We hold that an expert's description of forces generated during a collision is not medical testimony."

In 2015, in a case that also reached the WA Supreme Court, L.M. $v$ Hamilton, the court addressed the specific issue which has often been a key component to objections regarding my testimony, that I do not hold a medical degree and am therefore not qualified to opine regarding injury. The Court stated: 
"When determining whether a witness is an expert, courts should look beyond academic credentials. For example, depending on the circumstance, a nonphysician might be qualified to testify in a medical malpractice action. The line between chemistry, biology, and medicine is too indefinite to admit of a practicable separation of topics and witnesses. "The evidence rules say that a witness may qualify as an expert by knowledge, skill, experience, training, or education."

Other states in which I have testified (Idaho, Florida, Oregon, Nevada) have accepted these basic principles regarding biomechanical testimony.

\section{Conclusions}

A biomechanical analysis is ultimately a tool that can be used to explain the mechanics of an injury, which in my experience has covered a range of events including childbirth, falls, industrial injuries, sports injuries, domestic violence, child abuse, as well as motor vehicle accidents. Courts have generally accepted biomechanical testimony if it is based on accurate information about the incident and a sound analysis procedure that is accepted in the scientific field. Courts generally recognize that a biomechanical analysis can help the jury to understand the underlying cause of the injury and the level of forces to which the Plaintiff was exposed during the event.

\section{Legislation, cases}

Society of Automotive Engineers, Standard J885-12, Human Tolerance to Impact Conditions as Related to Motor Vehicle Design, 2012.

United States Department of Transportation, National Highway Traffic Safety Administration, 49 CFR Part 571 [Docket No. NHTSA-2004-19807] RIN 2127AH09 Federal Motor Vehicle Safety Standards; Head Restraints, 2008.

Washington State Appelate Court Division 2, Ma'ele v. Arrington, 565, 111 Wn. App. 557. Washington State Appellate Court Division 1, Stedman v Cooper, 172 Wn App 9, 292.

Washington State Appellate Court Division 2, Johnson-Forbes v Matsunaga, 177 Wn. App. 402, 311 P.3d 1260 (2013).

Washington State Supreme Court, L.M. v Hamilton, 200 Wn. App. 535, 402 P.3d, 870 (2017).

\section{References}

Barnsely, L., Lord, S. M., Wallis, B. J. et. al. (1995) The prevelance of chronic cervical zygapophysial joint pain after whiplash, Spine, 1995, 20(1), pp. 20-26.

Bartsch, A. J., Gilbertson, L. G., Prakash, V., Morr, D. R. \& Wiechel, J. F. (2008), Minor Crashes and "Whiplash « in the United States, Annals of Advances in Automotive Medicine, 52, pp. 117-130.

Eis, V., Sferco, R. \& Fay, P. (2005) A Detailed analysis of the characteristics of European rear impacts, The 19th Technical Conference on the Enhanced Safety of Vehicles, 
2005 (Washington, D.C. USA: National Highway Traffic Safety Administration).

Foust, D. R., Chaffin, D. B., Snyder, R. G. \& Baum, J. K. (1973) Cervical spine range of motion and dynamic response and strength of cervical muscles, SAE Transactions, 82(4), 730975, pp. 3222-3234, retrieved from https://www.jstor.org/stable/44721367 (October 15, 2019).

Happer, A. J., Hughes, M. C., Peck, M. D. \& Boehme, S. (2003) Practical analysis methodology for low speed collisions involving vehicles with modern bumpers, SAE Technical Paper, 2003-01-0492, doi: 10.4271/2003-01-0492.

Holm, L. W., Carroll, L. J., Cassidy, J. D., Hogg-Johnson, S., Cote, P., Guzman, J., Peloso, P, Nordn, M, Hurwitz, E., van der Velde, G., Carragee, E. \&, Haldeman, S. (2008) The burden and determinants of neck pain in whiplash-associated disorders after traffic collisions: results of the BBone and Joint Decade 2000-2010 Task Force on Neck Pain and its Associated Disorders, Spine, 2008, 33(4 suppl), pp. S52-S59, doi: 10.1097/BRS.0b013e3181643ece.

Howard, R. P., Bomar, J. \& Bare, C. (1993) Vehicle restitution response in low velocity collisions, SAE Technical Paper Series, Future Transportation Technology Conference \& Exposition, 931842, doi: 10.4271/931842.

Insurance Institute for Highway Safety (1995) Whiplash Injuries. Status Report, 30(8), pp. 1-12, September 16, 1995.

Krafft, M., Kullgren, A., Malm, S. \& Ydenius, A. (2005) Influence of crash severity on various whiplash injury symptoms: a study based on real-life rear-end crashes wth recorded pulses, In: The 19th Technical Conference on the Enhanced Safety of Vehicles, 2005 (Washington, D.C. USA:, National Highway Traffic Safety Administration).

McConnell, W. E., Howard, R. P., Van Poppel, J. et al. (1995) Human head and neck kinematics after low velocity rear end impacts: Understanding whiplash, $S A E$ Technical Paper Series, 39th Stapp Car Crash Conference (1995), 952724, doi: 10.4271/952724.

Merrick, D, \& Stalnacke, B. M. (2010) Five years post whiplash injury: Symptoms and psychological factors in recovered versus non-recovered, BMC Research Notes, 2010, 3: 190, pp. 1-8, doi: 10.1186/1756-0500-3-190.

O’Neill, B., Haddon, W. Jr. \& Kelly, A. B. et al (1972) Automobile head restraints -: Frequency of neck injury claims in relation to the presence of head restraints, American Journal of Public Health, 62(3)1972, pp. 399-405, doi: 10.2105/AJPH.62.3.399.

Ono, K., Kaneoka, K., Wittek, A. et al (1997) Cervical injury mechanism based on the analysis of human cervical vertebral motion and head-neck-torso kinematics during low speed rear impacts, SAE Technical Paper Series, 41st Stapp Car Crash Conference, 973340, doi: 10.4271/973340.

Radanov, B. P. \& Sturzenegger, M. (1996) The effect of accident mechanisms and initial findings on the long term outcome of whiplash injury, Journal of. Musculoskeletal Pain, 1996, 4(4), pp. 47-59, doi: 10.1300/J094v04n04_06.

Radanov, B. P., Sturzenegger, M. \& Di Stefano, G. (1995) Long term outcome after whiplash injury. A 2-year follow-up considering features of injury mechanism and somatic, radiologic, and psychosocial findings, Medicine, 1995, 74(5), pp. 281-297.

Sarrami, P., Armstrong, E., Naylor, J. M. \& Harris, I. A. (2017) Factors prediciting outcome in whiplash injury: a systematic meta-review of prognostic factors, Journal of Orthopaedics and Traumatology, 2017, 18(1), pp. 9-16, doi: 10.1007/s10195-0160431-x.

Siegmund, G. P., King, D. J. \& Montgomery, D. T. (1996) Using barrier impact data to 
determine speed change in aligned low speed vehicle to vehicle collisions, $S A E$ Technical Paper Series, International Congress \& Exposition, 960887, doi: $10.4271 / 960887$.

Spitzer, W. O., Skovron, M. L., Salmi, L. R. et al (1995) Scientific monograph of the Quebec task force on whiplash associated disorders, Spine, 1995, 20(8 Suppl), pp. 1S-73S.

Tanner, C. B., Wiechel, J. F., Bixel, R. A., Cheng, P. H. \&, Guenther, D. A. (2001) Coefficiants of restitution for low and moderate speed impacts with non-standard impact configurations, SAE Technical Paper Series, SAE 2001 World Congress, 2001-01-0891, doi: 10.4271/2001-01-0891.

Tencer, A. F. \& Mirza, S. K. (2000) Whiplash mechanics in low-speed rear-end automobile accidents, Journal of Musculoskeletal Pain, 8(1/2), pp. 69-86, doi: 10.1300/J094v08n01_062000.

Tencer, A. F., Mirza, S. K., Nicholson, R. et al (2000) Development of a retrofit car seat head restraint with potential to reduce cervical spine Whiplash injury, In: Proced of the ISATA International Conference on Automotive Technology, Dublin, Ireland, September, 2000.

Yadla, S., Ratliff, J. K. \& Harrop, J. S. (2008) Whiplash: diagnosis, treatment, and associated injuries, Current Reviews in Musculoskeletal Medicine, 2008, 1(1), pp. 65-68, doi: 10.1007/s12178-007-9008-x. 